\title{
Outcomes of conservatively managed coracoid fractures in wild
}

\section{birds in the United Kingdom}

Jonathan M. Cracknell BVMS CertVA CertZooMed MRCVS ${ }^{1}$

Alistair M. Lawrie BVMS HonFRCVS ${ }^{2}$

Lisa Yon BSc DVM PhD MRCVS

Jane S. Hopper MA VetMB CertZooMed MRCVS ${ }^{4}$

Yolanda Martinez Pereira LdaVet CertVC DipECVIM-CA (Cardiology) MRCVS ${ }^{5}$

Eve Smaller BSc(Hons) ${ }^{6}$

Romain Pizzi BVSc MSc DZooMed DipECZM MACVS(Surg) FRES FRGS FRSB MRCVS ${ }^{2,3,7^{*}}$

* author for correspondence

\section{Affiliations}

1) Wildlife Anaesthesia Services, Southview Park Street, Heytesbury, Warminster,BA12 OHQ, United Kingdom, tel: +44 7855 763319, email: jonwildvet@gmail.com

2) Scottish SPCA National Wildlife Rescue centre, Fishcross, Clackmannanshire, FK10 3AN, United Kingdom; Lawrie Veterinary Group, 25 Griffiths St, Falkirk, Stirlingshire FK1 5QY; tel: +44 7702 000767, email: a.lawrie@talk21.com;

3) School of Veterinary Medicine and Science, University of Nottingham, Sutton Bonington, Leicestershire, LE12 5RD, United Kingdom, tel: +44 1159 516358, email: lisa.yon@nottingham.ac.uk 4) Aspinall Foundation, Port Lympne Reserve, Aldington Rd, Lympne, CT21 4LH, United Kingdom, tel: 01303 234175, email: jane@aspinallfoundation.org

5) Royal (Dick) School of Veterinary Studies, University of Edinburgh, EH25 9RG, United Kingdom, tel: +447743 947802, email: yolanda.martinez@ed.ac.uk

6) Royal Veterinary College, University of London, 4 Royal College Street, London, NW1 0TU, tel: +44 7595945141 email: evesmaller@hotmail.co.uk 
7) Scottish SPCA National Wildlife Rescue centre, Fishcross, Clackmannanshire, FK10 3AN, United Kingdom; Royal Zoological Society of Scotland, Edinburgh Zoo, Corstorphine Road, EH12 6TS, United Kingdom; School of Veterinary Medicine and Science, University of Nottingham, Sutton Bonington, Leicestershire, LE12 5RD, United Kingdom, tel: +44 7761982404, email: rpizzi@rzss.org.uk 


\section{Abstract}

Coracoid fractures are a frequent presentation in wild birds, commonly due to collisions with motor vehicles, windows, or other obstacles such as pylons. Despite this, there are few literature reports of outcomes, and those published consist of small numbers of animals, with conflicting results when comparing conservative management with surgical intervention. Outcomes of 232 adult wild birds in the United Kingdom (UK), surviving more than 48 hours after admission, with only closed unilateral coracoid fractures confirmed on radiography were retrospectively analysed. There was a high success rate for conservative management, with $75 \%$ (95\% confidence interval of $69-80 \%$, $n=174 / 232$ ) of all birds successfully released back to the wild. The proportion of raptors successfully returned to the wild was even higher at $97 \%(95 \% \mathrm{Cl} 85-99 \%, n=34 / 35)$. A statistically significant difference of $26 \%$ ( $95 \% \mathrm{Cl}$ of $18-34 \%$, Fishers exact test $p<0.001, \mathrm{Z}=6.08$ ) was demonstrated, when comparing the raptor outcomes $(97 \%$ success, $n=34 / 35)$ to the non-raptor outcomes $(71 \%$, $\mathrm{n}=140 / 198)$. The median time in captive care until released back to the wild was 30 days $(95 \% \mathrm{Cl} 27$ 33 days). Conservative management of coracoid fractures in wild birds in the UK, and in particular in raptors, appears to result in good outcomes. The approach is low cost and non-invasive, in contrast to surgery, and is recommended as the first line approach of choice in these cases.

Running title: Coracoid fracture conservative management outcomes

Keywords: Avian, coracoid, fracture, bird, surgery, orthopedic

\section{Introduction}

In flying birds, the coracoid acts as a supporting strut between the wing and sternum ${ }^{1,2}$. Coracoid fractures are a common presentation in wild birds. They frequently result from collisions with motor vehicles, windows, or other obstructions such as pylons ${ }^{3,4}$, and affected birds are unable to gain lift ${ }^{4-6}$. Despite the common presentation of this injury, the small number of previous studies on 
treatment outcomes have been limited by the low numbers of birds managed conservatively, and reports with conflicting findings ${ }^{4,6}$. Scheelings ${ }^{4}$ reported an $89 \%(n=16 / 18)$ success rate for birds' return to the wild for conservatively managed coracoid fractures, whereas Holz ${ }^{6}$ reported only a $22 \%(n=2 / 9)$ success rate. The remainder of the publications on treatment outcomes from this injury are predominately single surgical case reports ${ }^{7,8}$, or expert opinion clinical experience reviews ${ }^{9-12}$; the Oxford Centre for Evidence Based Medicine ranks such papers as providing the lowest level of available evidence by which to make informed clinical decisions ${ }^{13,14}$.

Conservative management of fractures in wild birds holds multiple advantages, such as low cost in comparison to surgery; lower stress for wild birds undergoing rehabilitation for return to the wild, with likely reduction in stress-associated co-morbidities ${ }^{15}$; no risk of post-operative complications such as wound infections or dehiscence; and reduced anaesthesia risk, as anaesthesia is only required briefly for radiographic diagnosis ${ }^{4,16,17}$. Less time is also needed to treat an individual by veterinarians involved, freeing up resources to treat other cases. Some authors only recommend conservative management of coracoid fractures in birds weighing less than 300 grams $^{1,4,5,18}$. Coaptation, such as with a figure-of-eight bandage to immobilize the wing to the body, has been reported as useful ${ }^{5,18,19}$, but prolonged immobilization of wings risks changes such as propatagium contraction and a decreased elbow range of motion ${ }^{20}$. Schelling's study did not utilise coaptation in any of the 16 birds successfully returned to the wild after conservative management ${ }^{4}$.

This study aimed to evaluate the outcomes of a larger number of conservatively managed coracoid fractures in wild birds than previously published studies, with the calculation of confidence intervals relevant for future evidence based clinical decision making, and to aid comparison with previous studies and any other future study outcomes with different sample sizes.

\section{Materials and methods}


Wild birds in the United Kingdom admitted for treatment, rehabilitation, and return to the wild were selected for this study. All birds were rehabilitated in a single centre (Scottish Society for the Prevention of Cruelty to Animals National Wildlife Rescue Centre, Fishcross, Clackmannanshire) for consistency. Adult birds, surviving more than 48 hours after admission, and only those with closed unilateral coracoid fractures confirmed on radiography were included. Birds that had been shot, or had other long bone fractures, were excluded, as were birds with luxation of the shoulder, elbow or any other joints. Only birds with mild to moderate or no wing droop ("dropped shoulder") were included. Any birds with a wing droop to the extent of primaries actually touching or dragging on the ground were excluded, to aid eliminating cases where neuropathies or feather damage could inadvertently influence outcome. Fracture severity was classified in 3 grades to determine if these influenced outcomes: 1) minimal displacement, simple fracture; 2) moderate displacement of fracture ends, or comminuted fracture, with up to 3 fragments; 3 ) severe displacement of fracture ends, or moderate displacement as well as comminuted fracture.

Birds were managed by initial cage rest for 2-3 weeks. Standard analgesia was with meloxicom (Metacam, Boehringer Ingelheim, Bracknell, West Berkshire RG12 8YS, United Kingdom, 0.2 mg/kg po, sid for 7 days), but in individual cases this was extended, or administered at a higher dose, dependant on the individual clinician's assessment ${ }^{21,22}$. Cages were individual and too small to allow any flight, and in the case of raptors too small to allow the wings to be fully extended. No birds had any external coaptation, such as figure of eight bandages, applied, regardless of whether any wing

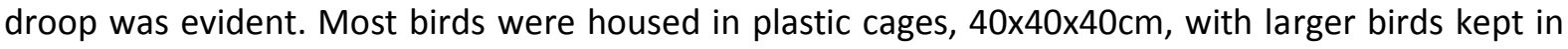
cages $80 \times 80 \times 80 \mathrm{~cm}$. While raptors were medicated in their food, all other bird species required handling for medication. During initial cage rest, all birds were handled once daily for the cages to be cleaned, surfaced, and fresh food provided, so medication administration was administered at the same time. After the second week, birds were given a weekly flight test, and once flying reasonably, and able to gain lift, were moved to seclusion aviaries to build strength. Raptors were moved to 
individual aviaries, whereas other birds were placed in group aviaries, to limit stress during rehabilitation.

After a successful flight test in a 15 meter corridor flight, all birds had a minimum of 1 week in an aviary (individual isolation aviaries for raptors and larger birds; social birds housed communally), and social aviaries for songbirds and columbiformes. Slow motion video recordings of raptors were assessed to confirm they were suitable for release, and identify any abnormal wing motion or use (iphone 6, Apple Inc). In all cases a visual assessment was made of the birds ability to gain lift, sustained flight, manoeuvrability, and ability to alight accurately on a perch from flight, by one of the veterinarians. A proportion of the raptors were admitted already rung, and outcomes of these birds were monitored through British Trust for Ornithology (BTO) ring returns. Live vertebrate prey testing is illegal in the United Kingdom under the Animal Welfare Act, 2006, and hence is not part of wildlife rehabilitation in the country.

Statistical analysis was performed via Minitab 17, and Confidence Interval Analysis for Windows 2.2.0. The normality of data was tested via Anderson-Darling tests. Where data was not normally distributed, non-parametric analysis was performed. Statistical significance was calculated at the 95\% confidence level.

\section{Results}

232 wild birds of a range of species met the criteria for inclusion in this study. There was a high success rate for conservative management (Table 1), with 75\% (95\% confidence interval of $69-80 \%$, $n=174 / 232$ ) of all birds successfully released back to the wild. This is compared to previous studies' findings in figures 1 and 2 . The proportion of raptors successfully returned to the wild was even higher at $97 \%$ (95\% Cl 85-99\%, $n=34 / 35)$. A statistically significant difference was demonstrated, when comparing the raptor outcomes (97\% success, $n=34 / 35)$ to the non-raptor outcomes $(71 \%$, 
$n=140 / 198)$; this was a difference of $26 \%(95 \% \mathrm{Cl}$ of $18-34 \%$, Fishers exact test $p<0.001, Z=6.08)$. No BTO rung dead returns were encountered within 2 months of release. Individual species included in this retrospective study, and the numbers seen, are listed in Table 2.

There was no statistically significant correlation of the grading of severity of fractures with outcome (Pearson correlation coefficient $0.274, p=0.476$ ). There was also no statistical significant difference in outcome between birds with a "dropped shoulder" and those without (Pearson correlation coefficient $-0.101, p=0.798)$.

The median time in captive care until release back to the wild was 30 days. Interestingly, the median time for raptors was 25.5 days ( $95 \%$ confidence interval of $24-27$ days) ,compared to 32 days in nonraptor species (95\% $\mathrm{Cl} 30-36$ days) , a Mann Whitney test point estimate median difference of 7 days (95\% confidence interval of $1-11$ days), demonstrating statistical significance $(p<0.02, W=1856)$. The difference was even more pronounced between raptors and columbiformes (Figure 3), which had a median time to release of 35.5 days $(95 \% \mathrm{Cl} 32-47$ days), with a Mann Whitney test point estimate median difference of 11 days (95\% confidence interval of 6-16 days), also demonstrating statistical significance $(p<0.0001, W=1136)$.

\section{Discussion}

The results of this retrospective study were in line with those of Scheelings ${ }^{4}$, who reported that $89 \%$ (95\% Cl $67-97 \%, n=16 / 18)$ of conservatively managed birds were successfully rehabilitated and released back into the wild, rather than those of $\mathrm{Holz}^{6}$ with a successful release rate of only of $22 \%$ $(95 \% \mathrm{Cl} 6-55 \%, \mathrm{n}=2 / 9)$ for conservatively managed fractures. However, the release rate in our much larger retrospective study group appeared lower than Scheelings', at $75 \%$ (85\% Cl $69-80 \%)$, but the apparent difference between this study and Scheelings' ${ }^{4}$ was not statistically significance $(95 \% \mathrm{Cl}$ of the difference $-24 \%$ to $8 \% ; p>0.05)$. The release rate of conservatively managed birds in this study 
were comparable to those reported for birds treated surgically by $\mathrm{Holz}^{6}$, who also had a $75 \%$ release rate (95\% Cl 41-93\% $\mathrm{n}=6 / 8)$, although he had a notably smaller sample size (Figures 1 and 2 ).

Although some authors have recommended coaptation such as figure of eight bandaging for coracoid fractures, others have concluded this to be unnecessary ${ }^{4}$. The avian coracoid is surrounded by a large muscle mass which appears to provide sufficient stability on its own. It remains for future studies to demonstrate if there is a statistically significant and clinically relevant difference if conservatively managed coracoid fractures are additionally provided with coaptation bandaging, in addition to analgesia and cage rest, as this entails increased time, costs, and handling of affected birds, with the associated increase in stress.

The differences between surgical treatment success rates in the two previously reported studies may have been influenced by a number of factors including differences in surgical experience, techniques and equipment available. The finding from the current study, that rates of release for conservatively managed cases were comparable to the best outcomes previously reported for surgical cases, lends weight to the recommendation that conservative management of these fractures should be the initial treatment of choice in the majority of cases, irrespective of body weight. These findings may hold relevance for captive birds, such as zoo raptors that encounter coracoid fractures. These birds may not require the same athletic perfection as wild raptors, even when used in flight displays, but the lower case volume in a zoological collection, combined with a higher perceived value of the individual animals, could favour a surgical approach to these cases management in some zoos, due to previous conflicting evidence ${ }^{4,6}$.

Difference in time to release for raptors was likely due to their individual management (as compared to non-raptors), including their pre-release monitoring in individual aviaries. The majority of other birds, including all columbiformes, were kept in groups in aviaries after their initial cage rest, to 
reduce stress, and then released as a group. An individual bird may well have been suitable for earlier release, but this didn't happen because of the batch release policies employed. As a result, the difference in time to release between raptors and other species groups may be artefactual, and not due to more rapid healing in raptors. This is consistent with findings from other studies ${ }^{4}$.

Heavier bird species, such as geese and gulls had a slightly poorer success rate than other birds. Different authors have conflicting opinions on whether or not body weight is an accurate predictor of the success of conservative management of coracoid fractures ${ }^{4,6}$. Outcomes in this study were still acceptable and provide support for this low cost treatment of some non-raptor species which may otherwise not be treated surgically in situations with financial or surgical constraints.

The raptors had a notably higher successful release rate than other smaller birds. This may have been due to the ease with which other injuries, such as shoulder luxations, could be easily detected on clinical examination, via palpation and radiographs, due to their size, whereas this was more difficult to assess in some columbiformes, and particularly in small passerine species. As all birds of different species were equally handled once daily, this should have had no additional impact on the outcomes, and is not believed to account for the difference in time to release difference in bird species.

While no dead returns were encountered within 2 months of release, in common with the majority of individual wildlife rehabilitation releases, the exact long term outcome of the majority of the birds is unknown. Detailed post-release monitoring of birds, as for any wildlife rehabilitation intervention would help evaluate longer term post release survival, to better inform decision making on the management of coracoid fractures in different avian species ${ }^{4}$.

\section{Conclusion}


Conservative management of closed coracoid fractures in birds without significant wing droop, with cage rest and analgesia, appears to yield a good success rate, irrespective of fracture severity, and is recommended as the first line treatment of choice for the majority of cases. The long term postrelease survival of these wild cases is unclear. These findings may also be relevant to the management of captive birds, such as those held in zoological collections, or used for falconry. 


\section{References}

1. Orosz SE. Avian surgical anatomy : thoracic and pelvic limbs. Philadelphia, London: WB Saunders; 1992.

2. King AS, McLelland J. Birds: Their Structure and Function. Eastbourne, UK: Bailliere Tindall; 1984.

3. Cousins RA, Battley PF, Gartrell BD, Powlesland RG. Impact injuries and probability of survival in a large semiurban endemic pigeon in New Zealand, Hemiphaga Novaeseelandiae. J Wildlife Dis. 2012; 48(3): 567-574.

4. Scheelings TF. Coracoid fractures in wild birds: a comparison of surgical repair versus conservative treatment. J Avian Med Surg. 2014; 28(4): 304-308.

5. Martin H. Orthopedic surgical techniques. In. Ritchie BW, Harrison GJ, Harrison LR, (eds.). Avian medicine : principles and application. Wingers Pub., Lake Worth, Fla.; 1994: 11371169.

6. Holz, P. Coracoid fractures in wild birds: repair and outcomes. Aust Vet J. 2003; 81(8): 469471.

7. Davidson JR, Mitchell MA, Ramirez S. Plate Fixation of a Coracoid Fracture in a Bald Eagle (Haliaeetus leucocephalus). J Avian Med Surg. 2005 19(4): 303-308.

8. Guzman DS, Bubenik LJ, Lauer SK, Vasanjee S, Mitchell MA. Repair of a Coracoid Luxation and a Tibiotarsal Fracture in a Bald Eagle (Haliaeetus leucocephalus). J Avian Med Surg. 2007; 21(3): 188-195.

9. Bowles H, Lichtenberger M, Lennox A. Emergency and Critical Care of Pet Birds. Vet Clin North Am Exot Anim Pract. 2007; 10(2): 345-394.

10. Graham JE, Heatley JJ. Emergency Care of Raptors. Vet Clin North Am Exot Anim Pract. 2007; 10(2): 395-418. 
11. de Matos R, Morrisey JK. Emergency and Critical Care of Small Psittacines and Passerines. J Exotic Pet Med. 2005; 14(2): 90-105.

12. Redig P, Francisco ON, Froembling M, Martinez LC. Coracoid fracture Management in Raptors: Assessment of the Conservative Approach. Milwaukee, Wisonsin, USA; Assoc Avian Vet, 2009; 351.

13. Guyatt GH, Oxman AD, Vist GE, Kunz R, Falck-Ytter $Y$, Alonso-Coello P, Schunemann HJ. GRADE: an emerging consensus on rating quality of evidence and strength of recommendations.(Grading of Recommendations Assessment, Development and Evaluation). BMJ. 2008(7650); 336: 924.

14. The Oxford Centre for Evidence Based Medicine Levels of Evidence. OCEBM Table of Evidence. http://www.cebm.net/index.aspx?o=5653. Accessed July !, 2017.

15. Bueno I, Redig PT, Rendahl AK. External skeletal fixator intramedullary pin tie-in for the repair of tibiotarsal fractures in raptors: 37 cases (1995-2011). J Am Vet Med Assoc. 2005; 247(10): 1154.

16. Bennett RA, Kuzma AB. Fracture Management in Birds. J Zoo Wildl Med. 1992; 23(1): 538.

17. Bennet R. Orthopedic surgery. In. Altman RB, (ed.). Avian medicine and surgery. Philadelphia: Saunders; 1997; 733-767.

18. Orosz SE 2002. Clinical considerations of the thoracic limb. Vet Clin North Am Exot Anim Pract. 2002; 5(1): 31-48.

19. Orosz SE, Ponder JB. Cutting to the chase-part 1: wing fractures. Proc North Am Vet Conf. 2012: 1306-1308

20. Redig PT. The use of an external skeletal fixatorintramedullary pie tie-in (ESF-IM fixator) for treatment of longbone fractures in raptors. In: Lumeij JT, Remple JD, Redig PT, et al, eds. Raptor Biomedicine III Including Bibliography of Diseases of Birds of Prey. Lake Worth, FL: Zoological Education Network; 2000:239-253. 
21. Baert K, De Backer P. Comparative pharmacokinetics of three non-steroidal antiinflammatory drugs in five bird species. Comp Biochem Physiol C Toxicol Pharmacol. 2003; 134(1): 25-33.

22. Desmarchelier M, Troncy E, Fitzgerald G, Lair S. Analgesic effects of meloxicam administration on postoperative orthopedic pain in domestic pigeons (Columba livia). Am J Vet Res. 2012; 73(3): 361. 
Table 1. Successful release rate after rehabilitation: for all birds, and broken down by species groups

\begin{tabular}{|l|l|ll|l|l|}
\hline Group & Release & 95\% Confidence Interval & St Error & Number \\
\hline All wild birds & $75.00 \%$ & $69.05 \%$ & to $80.13 \%$ & $2.84 \%$ & $n=174 / 232$ \\
Columbiformes & $71.77 \%$ & $63.29 \%$ & to $78.95 \%$ & $4.04 \%$ & $n=89 / 124$ \\
Raptors & $97.14 \%$ & $85.47 \%$ & to $99.49 \%$ & $2.82 \%$ & $n=34 / 35$ \\
passerine birds & $80.95 \%$ & $60.00 \%$ & to $92.33 \%$ & $8.57 \%$ & $n=17 / 21$ \\
heavy (non-raptor) birds & $65.38 \%$ & $51.80 \%$ & to $76.85 \%$ & $6.60 \%$ & $n=34 / 52$ \\
\hline
\end{tabular}


Table 2. United Kingdom native wild bird species included in the study

\begin{tabular}{|lr|}
\hline Raptors & $\mathbf{n}=$ \\
Kestrel (Falco tinnunculus) & 12 \\
Common buzzard (Buteo buteo) & 11 \\
Sparrowhawk (Accipiter nisus) & 5 \\
Peregrine falcon (Falco peregrinus) & 3 \\
Tawny owl (Strix aluco) & 1 \\
Columbiformes & \\
Woodpigeon (Columba palumbus) & 62 \\
Feral pigeon (Columba livia) & 55 \\
Collared dove (Streptopelia decaocto) & 7 \\
Heavy birds & \\
Lesser black backed gull (Larus fuscus) & 17 \\
Herring gull (Larus argentatus) & 14 \\
Pink-footed goose (Anser brachyrhynchus) & 2 \\
Greylag goose (Anser anser) & 1 \\
Canada goose (Branta canadensis) & 1 \\
Black headed gull (Chroicocephalus ridibundus) & 1 \\
Other species & \\
Common starling (Sturnus vulgaris) & 9 \\
Jackdaw (Corvus monedula) & 7 \\
Magpie (Pica pica) & 5 \\
Blue tit (Cyanistes caeruleus) & 2 \\
Carrion crow (Corvus corone) & 3 \\
Eurasian blackbird (Turdus merula) & 3 \\
Woodcock (Scolopax rusticola) & 3 \\
European robin (Erithacus rubecula) & 3 \\
House sparrow (Passer domesticus) & 2 \\
Snipe (Gallinago gallinago) & 2 \\
Great tit (Parus major) & \\
\hline
\end{tabular}


Figure 1. Outcomes in conservative management of coracoid fractures, and $95 \%$ confidence interval bars, for previous studies, the previous studies combined, and this study

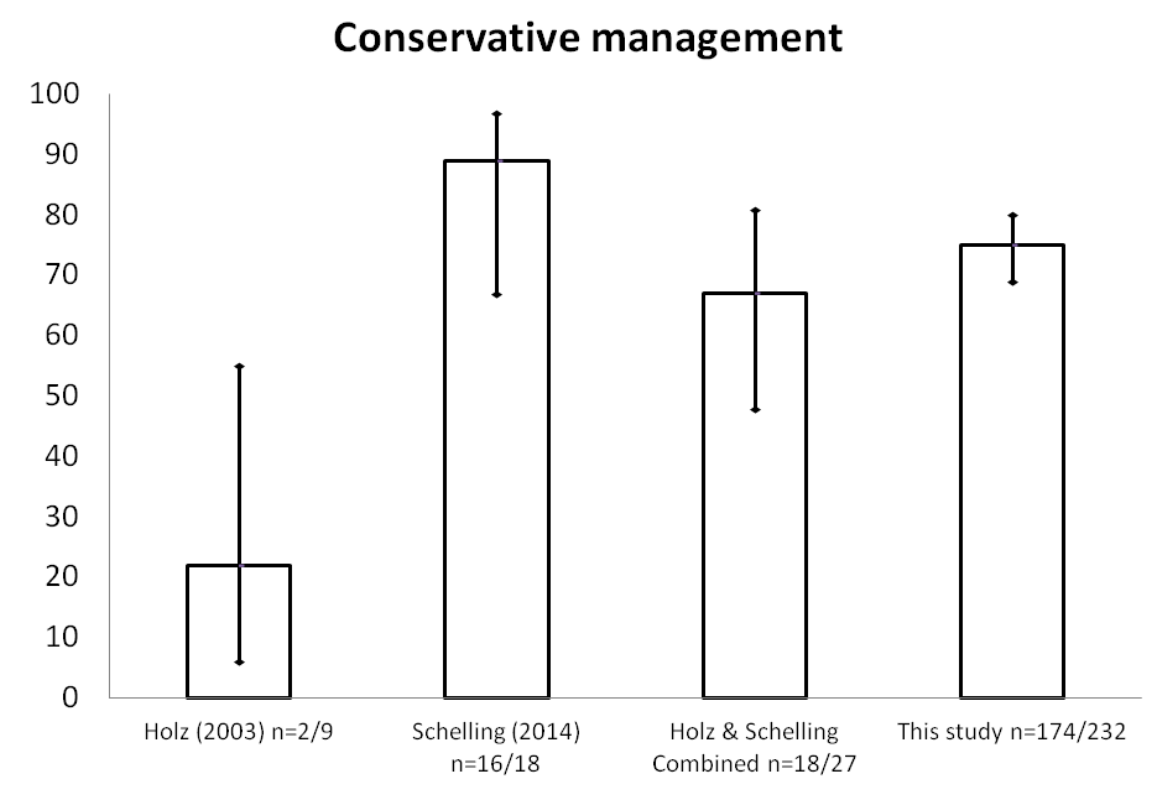

Figure 2. Outcomes in surgical management of coracoid fractures, and 95\% confidence interval bars, for previous studies, as well as for the previous studies combined

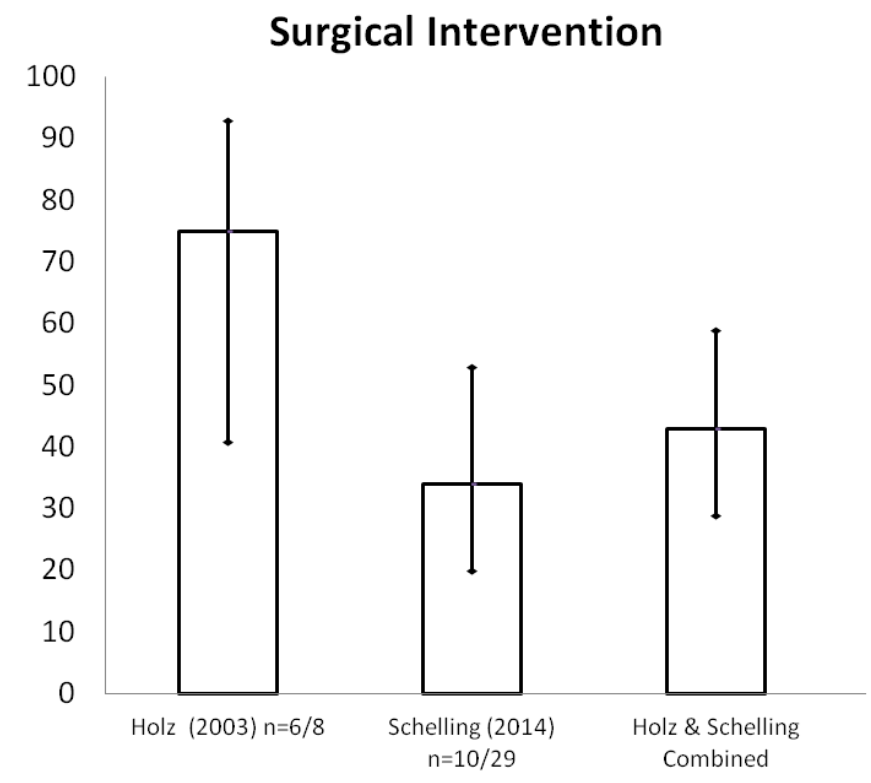


Figure 3. Boxplot comparing median number of days to release in raptors vs. columbiformes

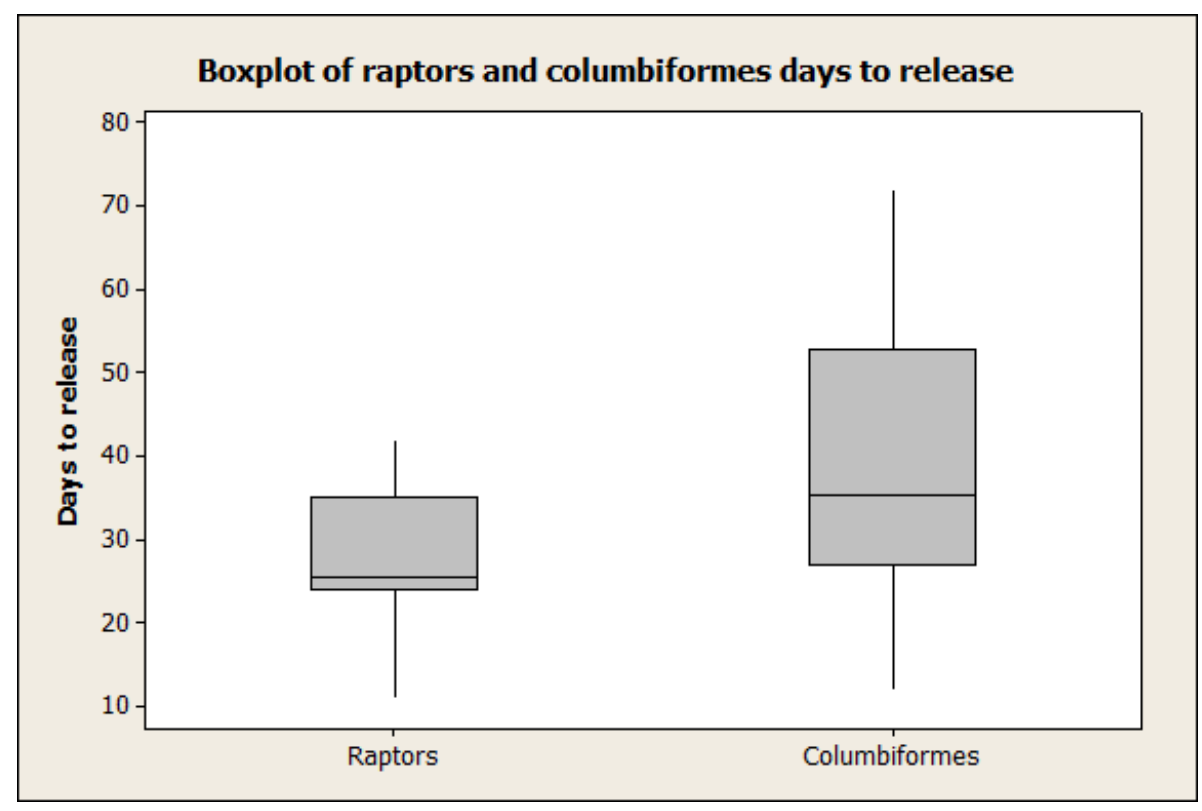

